\title{
DIAGNÓSTICO DE LA CADENA LOGÍSTICA DE EXPORTACIÓN DEL BANANO ECUATORIANO HACIA ESTADOS UNIDOS DE AMÉRICA*
}

\author{
Isidro José Fierro Ulloa ${ }^{1}$ \\ Carlos Ernesto Villacres Rojas ${ }^{2}$
}

\begin{abstract}
RESUMEN
La situación actual de la exportación del banano Ecuatoriano hacia el mercado de los Estados Unidos de América no atraviesa su mejor momento, limitantes como altos precios de producción se suman a problemas en la actual cadena logística, los cuales afectan la situación de este sector tan importante para la economía del país. Es así que para mejorar la competitividad del banano Ecuatoriano hacia los Estados Unidos de América este estudio se enfoca en diagnosticar sus puntos débiles en la cadena logística vigente a través de encuestas y entrevistas dirigidas a las Pequeñas y Medianas Empresas exportadoras con el fin de que se comercialice el banano Ecuatoriano sin intermediarios innecesarios. Dichos intermediarios encarecen el producto final, colocándolo en desventaja frente al banano de países exportadores de Centro América, debido a que en esta región el banano goza con facilidades como su cercanía geográfica con los Estados Unidos de América y su banano es de similares características al banano Ecuatoriano.
\end{abstract}

\section{PALABRAS CLAVES}

Exportaciones, Banano, Cadena Logística, Diagnosticar y Navieras.

\begin{abstract}
The current situation of the Ecuadorian banana export to the United States market is not at its best moment, limitations such as high production costs add up to the current logistic chain. This affects the situation of this sector, which is so important for the economy. Therefore, in order to improve the competitiveness of the Ecuadorian banana in the United States of America, this study focuses on a diagnosis of its weaker points in the current logistic chain through surveys and interviews given to small and medium sized exporting companies in order to avoid unnecessary intermediaries in the commercialization of the Ecuadorian banana. Such intermediaries make the final product more expensive, rendering it in a disadvantage point before other exporting countries in Central America, which have the privilege of being geographically closer to the United States of America, and whose banana has the same characteristics of the Ecuadorian banana.
\end{abstract}

\section{KEYWORDS}

Exports, Banana, Logistic Chain, Diagnosis and Shipping Line.

Depositado en febrero 16 de 2014, aprobado en mayo 23 de 2014.

*Artículo resultado de la investigación realizada para optar por el título de Ingeniero en Ciencias Empresariales, del Programa ICP, de la Universidad Espíritu Santo - UEES - Ecuador

$\overline{1 \text { MBA y PhD }}$ (c). Decano de la Facultad de Estudios Internacionales de la Universidad Espíritu Santo UEES, Ecuador. E mail: isfierro@ uess.edu.ec

2 Ingeniero en Ciencias Empresariales 


\section{INTRODUCCIÓN}

El banano Ecuatoriano es uno de los ejes de la economía de Ecuador, de tal manera que su disminución en volúmenes de exportación representa un fuerte golpe a la economía nacional. Es de tal forma que durante los últimos cinco años los volúmenes de exportación han decrecido a ciertos mercados como es principalmente el caso de los Estados Unidos de América (EE. UU).

No obstante, su disminución se debe a varias razones, entre ellas, la dura competencia con los países exportadores de Centro América. Existen condiciones geográficas de países como Guatemala, Costa Rica, México, Colombia las cuales en sus fletes marítimos no deban cruzar el canal de Panamá y sus tránsitos no superan los cinco días aproximados hacia EE. UU. Lo cual les permite comercializar una fruta de buena calidad a menor precio. En añadidura el déficit de políticas de comercio exterior por parte del gobierno de turno, mas la no negociación en bloque por parte de los exportadores, y finalmente la no implementación de una cadena logística integral para sus exportaciones agrava la situación de las comercialización para este mercado tan importante.

Sin embargo, según el libro La Economía Mundial del Banano 1985 - 2002, las exportaciones de banano en las últimas décadas hacia los EE. UU. han decrecido, de 1988 a 1990 las exportaciones a este mercado eran del 55 por ciento entre todos los destinos de exportación, después de 10 años, desde 1998 al 2000 las exportaciones a este mercado decrecieron a un 32 por ciento, tendencia que se mantiene en la actualidad (Arias, Dankers, Liu, \& Pikauskas, 2004).

De tal forma, con el presente diagnóstico se busca identificar las debilidades en la actual cadena logística en la exportación de banana hacia EE. UU., para así implementar una cadena logística integral para las Pequeñas y Medianas Empresas (PYMES) exportadoras de banano que ya no se ven atraídos por el mercado de los EE. UU. Se podrían eliminar intermediarios innecesarios con el fin de disminuir costos de producción y poder sostener un precio de venta final competitivo en comparación con el resto de países exportadores de banano.

Por consiguiente, el diagnóstico de la cadena logística de exportación del banano hacia los EE. UU., será relevante para implementar soluciones y mantener la presencia en los niveles de exportaciones del banano en este mercado.

\section{REVISIÓN DE LITERATURA}

La producción del banano ecuatoriano tiene sus orígenes en el año 1910, pero su boom tuvo como punto de partida el ano 1948 cuando el gobierno del señor presidente Galo Plaza fomentó la facilitación de créditos a los agricultores, adicionalmente se construyeron puentes, vías y puertos, los cuales facilitaron la exportación del banano a distintos destinos en el exterior (Valarezo \& Torres Dávila, 2004). En 1952 Ecuador fue considerado como el primer exportador de banano a nivel mundial, durante la década de los 50 tan solo 3 exportadoras tenían el control del ochenta por ciento de la producción de banano a nivel local. De tal manera, durante la década de los 60 , la producción y exportación del banano creció a pasos de gigante, convirtiendo al país en el primer proveedor de banano a nivel mundial. (Arias, Dankers, Liu, \& Pikauskas, 2004)

Dado que el banano cuenta con un alto contenido de hierro y una gran variedad de vitaminas que ayudan a regenerar los tejidos musculares, por consiguiente, los deportistas y nutricionistas recomiendan el consumo de esta fruta por sus ventajas para la recuperación durante el desarrollo de actividades físicas. Por otra parte, el banano es la fruta que más contiene potasio, el cual es uno de los minerales más necesarios y fundamentales para poder mantener una vida saludable, por su ayuda a la protección del cáncer de colon (Calabuig, 2012).

El Ecuador es un país el cual goza de muchos beneficios geográficos y climáticos los cuales permiten la producción de una amplia gama de productos alimenticios de características tropicales como lo son el banano, plátano, piñas, yuca, malanga u otros. Sin embargo, la economía del Ecuador se basa en la producción, co- 
mercialización del crudo y sus derivados; a pesar de lo antes mencionado, detrás del petróleo se encuentra la exportación de banano como la segunda mayor fuente de ingresos para la economía del país (Padilla, 2013).

La razón de la investigación es diagnosticar la actual cadena logística en la exportación del Banano Ecuatoriano al Mercado de los EE. UU., y se permita así implementar mejoras a partir del análisis del proceso logístico existente.

\section{DEFINICIÓN DE CONCEPTOS CLA- VES}

Cadena Logística

La Cadena Logística es el canal de movimiento de pasajeros y de mercancías desde su origen hasta el consumidor final. Ese movimiento se realiza a través del servicio, de la manipulación, transformación, desplazamiento y almacenaje que sufre el producto desde que es materia prima hasta la elaboración del producto final (Beato, 2011).

\section{Comercio Exterior}

El comercio exterior es el intercambio de bienes o servicios existente entre dos o más naciones con el propósito de que cada uno pueda satisfacer sus necesidades de mercado tanto internas como externas. Está regulado por normas, tratados, acuerdos, y convenios internacionales entre los países para simplificar sus procesos, y busca cubrir la demanda interna que no pueda ser atendida por la producción nacional (Comercio y Aduanas , 2012).

\section{Exportaciones:}

La exportación es un bien o servicio que es enviado a otra parte del mundo con fines comerciales. El envío puede concretarse por distintas vías de transporte, ya sea terrestre, marítimo o aéreo. Incluso, puede tratarse de una exportación de servicios que no implique el envío de algo físico (Definicion, 2010).

Naviera:

Las navieras constituyen un sector de servicios esencial en el mercado de la explotación de recursos y transporte de mercancías marítimos. Los servicios de reparación de barcos y todo tipo de buques y embarcaciones que ofrecen, así como el mantenimiento de los mismos, se constituyen como elementos esenciales en el campo de los negocios vinculados al mar (Portal Náutico, 2011).

\section{MARCO LEGAL}

Ecuador es un país democrático el cual se rige legalmente bajo la constitución 2008 aprobada en referéndum por la población. De tal forma, para el ejercicio de actividades relacionadas con el comercio exterior rigen:

- Código Orgánico de la Producción, Comercio e Inversiones.

- Ley de Comercio Exterior.

En consecuencia, las exportaciones de Banano Ecuatoriano hacia los EE. UU., deben basarse en las leyes reguladoras.

\section{Código Orgánico de la Producción, Comercio e Inversiones}

El Código Orgánico de la Producción, Comercio e Inversiones tiene cuatro ejes en los cuales se enfoca el presente código, tales como; políticas sustitutivas de importaciones, medidas de política industrial, verticales y selectivas, política de competitividad sistemática y el crecimiento económico sostenido.

De tal forma, los ejes tienen como argumentos el proteger la industria local, incentivando la producción basada en innovación tecnológica como también la regularización del las condiciones del mercado y una óptima diversificación de los sectores productivos.

\section{Ley de Comercio Exterior}

La Ley de Comercio Exterior tiene como objetivo;

Normar y promover el comercio exterior y la inversión directa, incrementar la competitividad de la economía nacional, propiciar el uso eficiente de los recursos productivos del país, y propender a su desarrollo sostenible e integrar la economía ecuatoriana con la internacional, y contribuir a la elevación del bienestar de la 
población (Ministerio de Comercio Exterior, 2012).

Así mismo, la ley de Comercio Exterior cita en su artículo número quince la importancia de promover la cooperación entre ministerios;

Art. 15.- Corresponde al Ministerio de Comercio Exterior, Industrialización y Pesca planificar, dirigir, controlar y ejecutar las políticas de comercio exterior de bienes, servicios y tecnología, integración e inversión directa función que la ejercerá en estrecha coordinación con el Ministerio de Relaciones Exteriores, y coordinar con las entidades del Sector público $\mathrm{y}$ del sector privado que conforman el sector Comercio Exterior, contribuyan a la debida ejecución de dichas políticas en el ámbito de sus respectivas competencias (Ministerio de Comercio Exterior, 2012).

A través del presente artículo, el cual busca promover las exportaciones agrícolas como lo es el banano, mediante un trabajo en conjunto del Ministerio de Comercio Exterior con el Ministerio de Agricultura, Ganadería, Acuacultura y Pesca (MAGAP).

No obstante, la Ley de Zonas Francas y Ley Orgánica de Aduanas también regulan las exportaciones de productos agrícolas hacia los distintitos destinos que demandan las frutas ecuatorianas.

\section{SECTOR EXPORTADOR DE BANANO EN EL ECUADOR}

El banano ecuatoriano es reconocido a nivel mundial por su calidad. Las exportaciones de banano representan el segundo mayor ingreso para el país. En consecuencia el $30 \%$ del banano que se consume a nivel mundial proviene desde Ecuador, es así que el país es considerado como el primer productor y exportador a nivel mundial (PROECUADOR, 2013).

En la actualidad las exportaciones de banano representan el sesenta por ciento del PIB agrícola del Ecuador, siendo el producto más exportado en el país después del petróleo (Sanbrailo, 2012). A pesar de ello existen varios países ex- portadores de Banano, como: Costa Rica, Colombia, Guatemala y Filipinas. Sin embargo, entre los países en mención es Ecuador quien lidera las exportaciones a nivel mundial. Según el portal de la Asociación de Exportadores de Banano del Ecuador (AEBE) Indica;

Ecuador desde 1952 es el primer exportador de bananos al mundo, con la única excepción de los años 1982 y 1983, cuando por efectos de un fenómeno natural, de El Niño, soportó el arrasamiento de gran parte de sus plantaciones, cediéndole este liderazgo a Costa Rica, segundo exportador a nivel mundial; pero en 1984 volvió a ocupar el liderazgo que lo mantiene, gracias a la forma de combinar los recursos de trabajo, técnica, inversión económica, administración y tierra (AEBE, 2013).

Es así como debido a la gran rentabilidad de este sector productivo del país, el número de exportadoras crece año tras año; pero sus principales exportadores a nivel local son tan solo cinco empresas, tales como A) Exportadora Noboa, B) Dolé, C) Reybanpac, D) Chiquita y E) Del Monte (HOY, 2008).

Según Juan José Pons el éxito de la exportadora Noboa se debe a sus orígenes en el cual sus ejecutivos destacan que la clave del éxito es mantener la estructura de bajo costo (De Cordoba, 1995).

\section{PROBLEMAS EN LA CADENA LOGÍS- TICA PARA LA EXPORTACIÓN DEL BANANO}

El banano Ecuatoriano se exporta hacia varios rincones del planeta, entre sus principales destinos se encuentran: Europa, Norte América, Medio Oriente, Cono Sur y Asia. Específicamente a países como EE. UU., Canadá, Inglaterra, Alemania, Holanda, Emiratos Árabes Unidos, Egipto, Chile, China y Japón, quienes son los principales importadores del banano Ecuatoriano (Osorio, 2012).

En Ecuador existen asociaciones de PYMES exportadoras de banano, las cuales buscan poder obtener certificaciones a nivel grupal, tales como responsabilidad ambiental, responsabilidad social 
y de comercio justo. De modo que los principales importadores prefieran la compra de su banano por dichas certificaciones (Padilla, 2013).

Sin embargo, la cadena logística para la exportación del sector bananero en el Ecuador implica varios integrantes, desde el productor hasta el consumidor final; la cadena logística es sin duda alguna el pilar para las exportaciones del banano. Hau Lee, uno de los principales expertos a nivel mundial en logística, indica que unos de los cuatro principios de la cadena de suministros es que "la competencia no es entre empresas sino entre cadenas de suministros" (Mecalux Esmena, 2012). Por tal razón, las empresas multinacionales como Dolé, Chiquita, Del Monte y Fyfles, poseen cadenas logísticas integrales en las cuales funcionan operadores logísticos propios o subcontratados con el fin de minimizar costos de producción.

En consecuencia, durante varios años la exportación del banano se realizó en la modalidad a granel, la cual comprende el embarcar las cajas de banano bajo las cubiertas refrigeradas de los barcos diseñados para movilizar frutas. Por tanto, la crisis económica global de 2008 que afectara al sector exportador de banano, se vio reflejada en el aumento del uso de contenedores refrigerados para la exportación del banano. Análogamente, previo a la crisis global en el año 2007, las exportaciones se realizaban en un $80 \%$ en buques al granel y solo un $20 \%$ en contenedores, pero actualmente el $60 \%$ del banano se exporta mediante las distintas líneas navieras y sus contenedores refrigerados (Agroban, 2012).

Por consiguiente, las líneas navieras cumplen un rol de suma importancia en la cadena logística de exportación del banano ecuatoriano hacia los EE. UU., u otros destinos, según el portal mexicano PRO MÉXICO, el cual indica lo siguiente (PRO MEXICO, 2013):

El transporte internacional representa dentro del área de servicios en el comercio internacional uno de los aspectos más importantes que deben conocer los operadores, tanto por la incidencia en los costos del mismo, por los riesgos que representa el traslado de una mercadería, como por las tareas operacionales paralelas que el mismo produce.
Así también, las tarifas spot ofrecidas por las líneas navieras para transportar el producto a los diferentes países generan costos mayores de producción, provocando que el precio final por caja de banano se incremente. A esto se suma los costos relacionados con el transporte terrestre desde los puntos de carga y consolidación del banano en contenedores, los mismos son altos, puesto que son empresas de terceros las que prestan estos servicios.

El diagnosticar los problemas en la actual cadena logística para la exportación del banano permitirá aplicar una cadena logística integral para la exportación del Banano que deberá estar conformada por el trabajo en conjunto desde su inicio a través de los productores del banano, transporte terrestre, empresas exportadoras, líneas navieras, agente de aduanas, importadores y hasta llegar al cliente final.

\section{SITUACIÓN ACTUAL DE LAS EXPOR- TACIONES DE BANANO}

Según el AEBE, durante el mes de agosto de 2013 los principales destinos de exportación son los siguientes (Véase tabla 1);

Tabla No 1. Destino de las Exportaciones de Banano durante agosto, 2013.

\begin{tabular}{|l|l|l|}
\hline \multicolumn{3}{|c|}{ AGOSTO - 2013 } \\
\hline DESTINO & VOLUMEN & $\%$ \\
\hline RUSIA & 5081.407 & $22.93 \%$ \\
\hline $\begin{array}{l}\text { EUROPA DEL } \\
\text { NORTE }\end{array}$ & 4489.269 & $20.25 \%$ \\
\hline USA & 3791.637 & $17.11 \%$ \\
\hline MEDIO ORIENTE & 3423.385 & $15.45 \%$ \\
\hline CONO SUR & 1901.11 & $8.58 \%$ \\
\hline MEDITERRANEO & 1310.658 & $5.91 \%$ \\
\hline EUROPA ESTE & 1289.144 & $5.82 \%$ \\
\hline ÁFRICA & 498.325 & $2.25 \%$ \\
\hline ORIENTE & 250.622 & $1.13 \%$ \\
\hline OCEANÍA & 129.432 & $0.58 \%$ \\
\hline TOTAL & 22164.989 & $100.00 \%$ \\
\hline
\end{tabular}

FUENTE: Asociación de Exportadores de Banano del Ecuador, AEBE (2013)

*Volúmenes en Cajas de Banano. 
En relación a las exportaciones de 2011 y 2012, el mercado para las exportaciones hacia los EE. UU., ha tenido una decaída significativa, mercados como Rusia, Europa y Medio Oriente cada vez son más atractivos para los exportadores de Banano.

Sin embargo, un país con una población de alrededor de 320 millones de habitantes como EE. UU., no sufre de una disminución de demanda de un producto alimenticio básico como lo es el banano.

De tal forma, hay varias razones por las cuales existe una disminución en las exportaciones de banano hacia los EE. UU., entre ellas, se encuentra la no implementación de una cadena logística integral para su exportación. A comparación de las multinacionales que están posesionadas en el mercado Americano, las PYMES exportadoras de banano en el Ecuador no ven atractivo la exportación de su producto hacia dicho mercado, barreras como permisos sanitarios, altos precios de fletes por parte de las navieras y un mercado copado por las multinacionales agrava la situación. El portal de la revista El Agro (2013), indica lo siguiente:

La cuota de participación en el mercado de Estados Unidos bajó del 23,67\% que tuvo en el primer trimestre de 2012, al 20,93\% en el primer trimestre de 2013. El representante de AEBE, indicó que esta situación se debe única y exclusivamente a que la principal compañía ecuatoriana bananera Noboa perdió ese mercado, dejó de enviar volúmenes importantes, y hoy envía apenas entre 20 a 30 mil cajas, de las 250 mil cajas que enviaba. Esa pérdida fue absorbida por los productores de Guatemala quienes coparon el mercado norteamericano, con una participación $395.805,5$ ton., frente a las $247.102,8$ ton., de Ecuador en el primer trimestre el 2013.

Es así que durante el 2012 las exportaciones de banano hacia los EE. UU., fueron lideradas por A) Guatemala (32\%), seguidas por; B) Ecuador (21\%), C) Costa Rica (20\%), D) Honduras $(11 \%)$, E) Colombia (9\%), F) México (4\%) y G) Nicaragua (1\%) (Portafolio, 2012).

En consecuencia, los países que escoltan a Ecuador en el ranking de exportadores de banano a nivel mundial, poseen una ventaja geográfica, puesto que cuentan con puertos en el Caribe y Pacifico con los cuales su cadena logística y operadores ofrecen niveles de fletes marítimos mucho más económicos en comparación a los ofrecidos en Ecuador. Incluso, Guatemala ha crecido de manera rápida en el mercado de los EE. UU., y Europa, a pesar que su producción no puede suplir la demanda de dichos países, existen dos empresas que operan en este país, las cuales negocian directamente con los supermercados, eliminando así a los intermediarios innecesarios, en este caso los importadores, con el fin de reducir el precio de su fruta. No obstante, en el Ecuador, aun los entes que negocian y promocionan el banano ecuatoriano tienen pendiente la misma tarea de desarrollar la comercialización con los grandes supermercados Europeos como TESCO y Norte-Americanos como Wal-Mart, COSCO u otros (Agroban, 2012).

A pesar de las noticias no tan alentadoras sobre los mercados de Norte América y Europa Norte para el banano Ecuatoriano, los exportadores han encontrado mercados alternos, los cuales son prometedores debido al aumento de la demanda del banano Ecuatoriano. Países como China y Rusia han desviado grandes niveles de exportación del banano ecuatoriano. Es así el caso que el mayor importador de banano en China, la empresa Dalian Ruihua ha visitado en varias ocasiones el país con el fin de reunirse con las partes involucradas como productores, exportadores, líneas navieras, autoridades e incluso el AEBE en el Ecuador (El Telégrafo, 2011).

Según el AEBE, el pionero en el mercado fué el señor Segundo Wong con la exportadora Rey Banano del Pacifico Reybanpac exportando inicialmente 6 mil toneladas métricas y llegando a un máximo de 10 mil. Durante el año 1995 se amplió a 60 mil toneladas métricas (AEBE, 2013).

Así mismo, la demanda en el mercado Ruso se ha incrementado durante los últimos años, por consecuente del 15 al 18 de septiembre de 2013 se llevó a cabo la feria World Food en la ciudad de Moscú, la cual fue promovida por Pro Ecuador a nivel nacional y contó con la presencia de varios exportadores de banano Ecuatoriano (World Food Moscow, 2013). 
Los incrementos de exportaciones hacia otros destinos no tradicionales se deben a las políticas de comercio exterior que promueve el gobierno de turno, enfocadas en el comercio con países de Asia, Latino América y África (E1 Comercio, 2014). Este es el ranking de las 10 primeras exportadoras a nivel nacional durante Enero a Agosto, (AEBE, 2013). (Véase tabla 2);

Tabla No 2. Principales Empresas Exportadoras de Banano en el Ecuador

\begin{tabular}{|l|l|l|}
\hline \multicolumn{3}{|c|}{2013} \\
\hline Exportadora & Total & $\%$ \\
\hline 1.- UBESA & 17926.850 & $22.34 \%$ \\
\hline 2.- TRUISFRUIT & 14562.905 & $18.15 \%$ \\
\hline 3.- REYBANPAC & 8071.539 & $10.06 \%$ \\
\hline 4.- COMERSUR & 7070.673 & $8.81 \%$ \\
\hline 5.- ORO-BANANA & 6664.432 & $8.31 \%$ \\
\hline 6.- ASOGRIBAL & 6169.560 & $7.69 \%$ \\
\hline 7.- BRUNDICORPI & 5544.821 & $6.91 \%$ \\
\hline 8.- ECUAGREENPRODEX & 5165.537 & $6.44 \%$ \\
\hline 9.- CORAGROFRUT & 4530.615 & $5.65 \%$ \\
\hline 10.- BAGNILASA & 4530.615 & $5.65 \%$ \\
\hline Total & 80237.547 & $100.00 \%$ \\
\hline
\end{tabular}

FUENTE: Asociación de Exportadores de Banano del Ecuador, AEBE (2013)

*Volúmenes en Cajas de Banano.

Es importante anotar que las multinacionales como DOLE son representadas a nivel nacional por Ubesa, parte del grupo Noboa, y Chiquita son representadas por la empresa Brundicorpi.

\section{METODOLOGÍA}

La investigación para diagnosticar la cadena logística de la exportación del banano ecuatoriano hacia los EE. UU., tiene un enfoque cualitativo debido a que se analizaron datos en los cuales se pudo obtener el criterio actual de los exportadores de banano y la situación por la cual atraviesa el sector. No obstante, se aplicó el enfoque cuantitativo ya que se analizan datos numéricos que se obtuvieron mediante las encuestas realizadas a las empresas exportadoras.

El diagnóstico de la cadena logística para la exportación de banano hacia los EE. UU., es un trabajo investigativo de carácter explicativo, debido a que se busca encontrar las razones o causas por las cuales las exportaciones hacia los EE. UU., están decreciendo paulatinamente. De tal forma, se busca explicar como la cadena logística afecta a la exportación del banano y su situación actual.

El trabajo investigativo diagnostica los problemas en la actual cadena logística para la exportación del banano Ecuatoriano hacia EE. UU, a través de un método Analítico Sintético, de manera que se distinguieran los componentes que conforman la cadena logística para la exportación de banano y se procedió a revisar cada elemento por separado y establecer sus ventajas y desventajas con el fin de proponer una cadena logística integral.

\section{Población y Muestra}

La población, de esta investigación, para el estudio de diagnóstico de la cadena logística para la exportación del banano hacia EE. UU., son las empresas exportadoras de banano Ecuatoriano, teniendo como objetivo las PYMES exportadoras. El total de exportadoras de banano registradas ante el MAGAP y el AEBE son 57, debido a que la Exportación de Banano representa el segundo mayor rubro por ingreso de divisas después de la exportación del crudo y derivados el crecimiento de las PYMES exportadoras se debe aquello y al "El aumento del banano en mercados como China el cual importó de Ecuador más de \$4.4 millones de dólares de banano durante el mes de Junio 2012, casi igualando al monto total de importaciones de todo el año 2011, que fue de $\$ 5$ millones." (Pro Ecuador, 2012).

Se reconocen las opiniones y preferencias de los exportadores de banano mediante la fórmula de muestra, la cual refleja una cantidad representativa de empresas, lo que sería el total de las PYMES exportadoras. 


\section{Fórmula de la Muestra}

El universo finito del estudio está conformado por las PYMES exportadoras de banano ecuatoriano en el Ecuador, que se conoce según el registro que lleva el MAGAP, quienes llevan el control de las empresas exportadoras, que llegaron a un total de 57. Del total de empresas, la muestra que se estudió fue obtenida mediante un método aleatorio, consistente en que la base de muestreo a investigar constituya un muestreo probabilístico, donde cada elemento tiene una posibilidad similar de ser escogido como parte de la muestra a usar.

$\mathrm{N}($ Tamaño de la población $)=57$ exportadoras $\mathrm{E}$ (Margen de Error) $=5 \%$

Nivel de confianza $=95 \%$

$\mathrm{N}($ Tamaño de la muestra $)=i ?$

El margen de error es del 5\%, lo que indica que el margen de confiabilidad permitido es del $95 \%$, el tamaño de muestra población es de 57 exportadoras, el resultado de la fórmula da 50, que será el tamaño de la muestra, la cual se usó para conocer opiniones y preferencias para la exportación del banano ecuatoriano. Así mismo, se analizó la viabilidad que ofrece el diagnóstico de la cadena logística de exportación del banano ecuatoriano hacia EE. UU., y el poder aplicar mejoras a la actual cadena logística.

\section{Técnicas e Instrumentos de investigación}

La información fue obtenida a través de encuestas recolectadas a la muestra específica de las PYMES exportadoras de Banano en el Ecuador. En la encuesta se realizaron preguntas como cuáles son sus principales destinos para la exportación del banano Ecuatoriano, también si considera atractiva la exportación de banano Ecuatoriano hacia los EE. UU., cuáles son las principales dificultades para exportar banano hacia EE. UU. De manera que las preguntas mencionadas y sus respectivas respuestas brindaron mayor conocimiento sobre las operaciones de las empresas exportadoras, destinos, tendencias, nuevas oportunidades y las principales razones para que las exportaciones de banano hacia EE. UU., decrecieran en comparación a años anteriores.
Las encuestas se realizaron vía email a las PYMES exportadoras, que son clientes de la línea naviera American President Line (APL). Además, se realizaron encuestas presenciales para que los exportadores puedan conocer más acerca del diagnóstico a la cadena logística de exportación del banano hacia EE. UU.; de manera, que los datos fueron recolectados de forma eficiente y apreciando las impresiones de las partes involucradas personalmente.

También se realizaron entrevistas a ciertos empresarios que exportan su banano hacia los EE. UU., como a aquellos que no exportan hacia el mercado en mención, reconociendo sus debilidades como fortalezas para poderlas representar en el diagnóstico, ya que a través esta información se determinará la viabilidad o acogida entre los exportadores con el fin de receptar las mejoras sugeridas por los encuestados y/o entrevistados.

Para llevar a cabo los propósitos de la presente investigación se aplicaron técnicas para obtener las respuestas o la información recolectada a través de las encuestas y/o entrevistas. Se utilizaron aquellas variables cualitativas que se describieron a través de Excel, las cuales fueron tabuladas diferenciando aquellas respuestas obtenidas por cada pregunta realizada a través de tablas dinámicas, filtros y la representación en gráficos de barras para una mejor interpretación. De tal forma se pudo conocer los porcentajes de la población encuestada que considera viable o no el diagnóstico de la cadena logística de exportación del banano ecuatoriano hacia EE. UU., y el poder aplicar mejoras a la actual cadena logística ya que los porcentajes reflejados, medidas y variables como desviación estándar, media, moda permitieron conocer a la empresa que fue encuestada.

Mediante la utilización del programa estadístico SPSS se realizaron la correlación y gráficos o tablas con dos o más variables, como lo son mercados de exportación, o si considera atractiva la exportación de banano hacia los EE. UU., y las complicaciones para exportar a este mercado. Se conoció así que el mercado objetivo está enfocado a evitar la exportación hacia los EE. UU., debido a razones múltiples o consi- 
Figura No 1. Tabla de Formulación de Muestra

\begin{tabular}{|c|c|c|c|}
\hline $\begin{array}{l}\text { ¿Qué porcentage de error quiere aceptar? } \\
5 \% \text { es lo más común }\end{array}$ & 5 & $\%$ & $\begin{array}{l}\text { Es el monto de error que usted puede tolerar. Una } \\
\text { manera de verlo es pensar en las encuestas de opinión, } \\
\text { este porcentage se refiere al margen de error que el } \\
\text { resultado que obtenga debería tener mientras más bajo } \\
\text { por cierto es mejor y más exacto. }\end{array}$ \\
\hline $\begin{array}{l}\text { ¿Qué nivel de confianza desea? } \\
\text { Las elecciones comunes son } 90 \%, 95 \%, \text { o } 99 \%\end{array}$ & 95 & $\%$ & $\begin{array}{l}\text { El nivel de confianza es el monto de incertidumbre que } \\
\text { usted está dispuesto a tolerar. } \\
\text { Por lo tanto,mientras mayor sea el nivel de certeza más } \\
\text { alto deberá ser este número, por ejemplo } 99 \% \text { y por } \\
\text { tanto,más alta será la muestra requerida. }\end{array}$ \\
\hline $\begin{array}{l}\text { ¿Cúal es el tamaño de la población? } \\
\text { Si no lo sabe use } 20.000\end{array}$ & 57 & & $\begin{array}{l}\text { ¿Cual es la población a la que desea testear? EI } \\
\text { tamaño de la muestra no se altera significativamente } \\
\text { para poblaciones mayores de } 20,000 \text {. } \\
\end{array}$ \\
\hline $\begin{array}{l}\text { ¿Cúal es la distribución de las respuestas ? } \\
\text { La elección más conservadora es } 50 \%\end{array}$ & 50 & $\%$ & $\begin{array}{l}\text { Este es un término estadístico un poco más } \\
\text { sofisticado, si no lo conoce use siempre } 50 \% \text { que es } \\
\text { el que provee una muestra más exacta. }\end{array}$ \\
\hline La muestra recomendada es de & 50 & & $\begin{array}{l}\text { Este el es monto mínimo de personas a testear para } \\
\text { obtener una muestra con el nivel de confianza } \\
\text { deseada y el nivel de error deseado. } \\
\text { Abajo se entregan escenarios alternativos para su } \\
\text { comparación }\end{array}$ \\
\hline
\end{tabular}

Fuente: Calculadora para obtener el tamaño de la muestra. Universidad Nordetes, 2004. Elaborado por: Carlos Villacres Rojas

dera aun viable el exportar hacia el mercado en mención. Con esta recolección de información se pudo obtener resultados que benefician a la investigación, puesto que es muy importante conocer si es viable la implementación de mejoras a la cadena logística para la exportación de banano hacia los EE. UU.

Con los resultados obtenidos de ambos programas se facilitó el análisis de datos obtenidos y, luego, la elaboración de conclusiones, recomendaciones y efectividad para alcanzar los objetivos planteados en el presente estudio.

\section{ANÁLISIS DE LOS RESULTADOS}

Según la información obtenida mediante encuestas, conformadas por ocho preguntas, las cuales fueron dirigidas a un grupo seleccionado de exportadores de banano ecuatoriano, clientes de la naviera APL, se pudo obtener información relevante para el diagnóstico de cadena logística para la exportación de banano hacia los EE. UU. Información detallada a continuación.

Se evidenció que el destino preferido para la comercialización del banano en el exterior es
Europa Norte y Rusia con un $50 \%$, existe un 25 $\%$ que actualmente exporta hacia los EE. UU., y el $25 \%$ restante a destinos varios.

Así mismo, El $80 \%$ de los exportadores si consideran atractivo el poder exportar el banano hacia los EE. UU., y tan solo un $20 \%$ respondió que no les parece atractivo el mercado en mención.

Entre los exportadores encuestados, las principales dificultades para exportar banano hacia los EE. UU., son varias y están planteadas así: el $30 \%$ considera que el mercado es muy competitivo; es decir, que esta manejado por multinacionales que no permiten el ingreso a las PYMES exportadoras; un $25 \%$ considera que los permisos sanitarios en destino también es una limitante; y un $25 \%$ consideró que todas las respuestas (precios de fletes marítimos, impuestos, otros) afectan a la exportación de la fruta hacia el destino del que nos ocupamos.

A su vez, el rango de tarifa para el flete marítimo que estaría dispuesto a pagar un exportador para el envío de su banano hacia los EE. UU., es bajo, debido a que la fruta resiste hasta 30 días 
de tránsito; por lo tanto, se busca reducir costos. En ese sentido, solo una empresa exportadora respondió que estaría dispuesta a cancelar el valor más alto con tal de que su fruta llegue lo más pronto posible, y así también, pagar el flete más alto con relación a precios.

Por otro lado, los exportadores consideran una dificultad la diferencia en precio de venta final del banano en comparación a exportadores de Centro-América, como; Costa Rica, Guatemala y Honduras, El $90 \%$ de los exportadores considera que la competencia con estos países es muy desigual debido a su geografía y su cercanía con los EE. UU. Lo cual influye en el precio final de la fruta y tan solo un $10 \%$ respondió lo contrario.

Así mismo, los exportadores creen que es viable disminuir el precio de la fruta mediante la implementación de una cadena logística integral (bajos precio de fletes, asociación de exportadores, eliminación de intermediarios) ya que el $85 \%$ respondió que sí es posible disminuir los precios mediante medidas integrales a la misma, y tan solo un $15 \%$ respondió que no sería viable.

Hay que considerar que las exportadoras encuestadas consideran atractiva la eliminación de intermediarios innecesarios entre las medida de implementación de una cadena logística integral para así disminuir el precio de venta final del Banano Ecuatoriano, y esto se debe al alto precio de la fruta que terminan pagando los clientes finalmente, pero hubo encuestados que respondieron que no consideran atractiva la propuesta de eliminar a los intermediarios innecesarios, la distribución fue $70 \%$ a favor y $30 \%$ en contra.

De manera que para poder llevar a cabo mejoras en el caso de implementar una cadena logística integral para la exportación del Banano Ecuatoriano hacia los EE. UU. los puntos más importantes a considerar para mejorar son:

- Acuerdos comerciales con los EE. UU.

- Limitantes con el MAGAP

- Mejoramiento a tarifas de fletes marítimos
Figura No 2. Gráfico Pastel sobre las dificultades para exportar banano hacia los EE. UU.

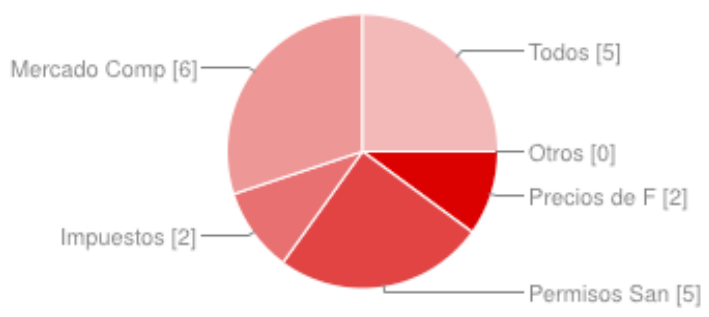

FUENTE: Elaboración propia basado en datos obtenidos mediante encuestas a exportadores clientes de la naviera APL.

Figura No 3. Gráfico de Barras sobre los problemas a mejorar en la actual cadena logística

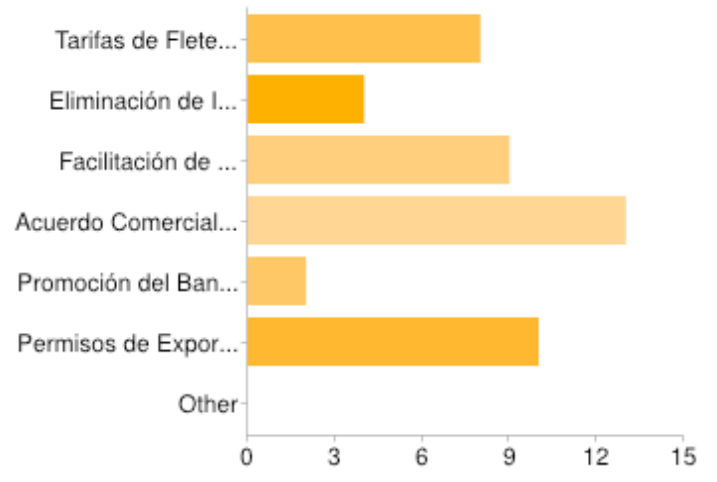

FUENTE: Elaboración propia basado en datos obtenidos mediante encuestas a exportadores clientes de la naviera APL.

\section{CONCLUSIONES}

Ecuador es un país rico en bondades geográficas y climáticas para la producción de banano, y la exportación del mismo se la ha realizado con éxito a la mayor parte de países que demandan su importación. No obstante, la disminución de volúmenes de banano ecuatoriano en el mercado de los EE. UU., por las razones antes mencionadas, disminuyen las posibilidades de incrementar su comercialización en un mercado caracterizado por su alto nivel de adquisición y gran tamaño de población.

Por consiguiente, el diagnóstico de la cadena logística para la exportación de banano ecuatoriano hacia los EE. UU., se basa en los siguientes temas y mejoras sobre puntos débiles, tales como: 
- Obtener mejores precios con las distintas líneas navieras que vayan a realizar la logística de su exportación.

- Asociar a los PYMES exportadoras con el fin de poder negociar en bloque las ventajas y beneficios para sus integrantes.

- Reducir costos de operación a nivel nacional, como mejoras en los precios de los fletes terrestres desde puntos de consolidación hasta el terminal de ingreso portuario.

- La eliminación de los intermediarios innecesarios, con el fin de comercializar la fruta directamente a las cadenas de supermercado que demandan el producto en los EE. UU.

- Tratar de igualar los precios o disminuir la brecha existente en el precio de venta con los países exportadores centro-americanos.

De tal forma el presente diagnóstico de la cadena logística de exportación del banano ecuatoriano hacia los EE. UU., permitirá igualar las condiciones de negociaciones del resto de países exportadores de banano como Guatemala, Costa Rica, Honduras, El Salvador y Colombia con presencia en dicho mercado, con el fin de incrementar las exportaciones hacia los EE. UU., que es el mayor socio comercial a nivel de exportaciones en toda la línea de bienes y productos producidos en el Ecuador.

\section{RECOMENDACIONES}

Mediante la presente investigación y a través del diagnóstico de la cadena logística de exportación del banano ecuatoriano hacia EE. UU., se podría aplicar mejoras para la exportación de banano ecuatoriano hacia este mercado. Se sugiere implementar cambios en los principales ejes integrantes de su cadena logística, tales como:

Productores.-

Los productores de banano ecuatoriano deben hacer respetar los precios de venta por caja bajo los contratos existentes en el MAGAP con los exportadores que compran su fruta para así mantener un precio estable por un año calendario; a su vez, el precio fijado deberá ser acorde al mercado previamente pronosticado y puede estar sujeto a cambios en caso de requerirse, y debido a situaciones que alteren el mercado nacional e internacional, para así evitar la inestabilidad de precios en las épocas altas y bajas de exportación del banano.

Transporte Terrestre.-

Los PYMES exportadoras de banano ecuatoriano deberían realizar inversiones en transporte terrestre propio para el traslado de la fruta desde los puntos de orígenes hasta los lugares de consolidación y terminales de ingreso portuario, con el fin de eliminar la contratación de empresas terceras, las cuales ofrecen el servicio pero a su vez incrementan los costos de producción debido a los altos costos.

Empresas Exportadoras.-

Las empresas exportadoras de banano ecuatoriano deberían presionar en conjunto a los organismos estatales pertinentes del comercio exterior en los gobiernos de turno y fomentar acuerdos Comerciales con los EE. UU., para así ingresar con mayor facilidad y menores barreras arancelarias.

Ministerio de Agricultura, Pesca y Ganadería (MAGAP).-

El ente principal en la regulación de las exportaciones de banano es el MAGAP, el cual aun mantiene medidas que afectan al desarrollo e incremento de las exportaciones del banano ecuatoriano, se debería realizar mejoras en las garantías para las exportaciones. En muchas ocasiones los exportadores se ven imposibilitados de incrementar volúmenes debido a que han cumplido con el límite de exportación en base a las garantías que poseen frente al MAGAP.

\section{Líneas Navieras.-}

Las empresas exportadoras de banano y el AEBE deberían establecer tarifas bajo contrato por un año calendario para así manejar precios y niveles de fletes marítimos equitativos durante el periodo de valides, de tal forma se eliminaran los altos precios y tarifas spot en la temporada alta de exportación.

Intermediarios Innecesarios.-

El promover la eliminación de intermediarios innecesarios como los importadores o brokers en la cadena logística de exportación de bana- 
DIAGNÓSTICO DE LA CADENA LOGÍSTICA DE EXPORTACIÓN DEL BANANO ECUATORIANO HACIA ESTADOS UNIDOS DE AMÉRICA

no permitirá a las empresas exportadoras comercializar su fruta directamente con cadenas de supermercados en el cual los clientes finales obtendrán un precio competitivo de venta.

De tal forma, que a través de mejoras en estos ejes se podrá impulsar el aumento de volúmenes y presencia del banano ecuatoriano en los EE. UU. Por consiguiente, estas propuestas permitirían un modelo de logística integral, reduciendo costos y aumentando competitividad. Así se podrá aplicar como guía para la exportación del banano hacia otros destinos donde existe una alta demanda como en Europa Norte, Rusia y otros países.

Por último, los organismos a cargo del comercio exterior y el gobierno de turno deberían basar sus políticas de Estado con base en ideologías exitosas como las propuestas por Milton Friedman de libertad de emprendimiento y la integración a la economía global, un gran ejemplo es Chile, país en el cual se generó que las exportaciones se multipliquen en más de 11 veces en términos reales (Silva, 2012).

\section{REFERENCIAS BIBLIOGRÁFICAS}

AEBE. (2013, 06 21). Asosiacion de Exportadores Banano del Ecuador. Retrieved 10 04, 2013, from Los Mercados Ruso y Chino: http://www.aebe.com.ec/Desktop.aspx?Id=46

Agroban. (2012, 08 20). CORPORACIÓN REGIONAL DE BANANEROS ECUATORIANOS. Retrieved 10 04, 2013, from MODALIDAD EN EL ENVÍO DEL BANANO REGISTRA CAMBIOS: $\underline{\text { http://agroban.com.ec/?p=379 }}$

Arias, P., Dankers, C., Liu, P., \& Pikauskas, P. (2004). La Economia Mundial del Banano 1985 - 2002. Italia, Roma: Organización de las Naciones Unidas para la Agricultura y La Nación.

Beato, N. (2011, 09 10). El Acento . Retrieved 11 16, 2013, from La Cadena Logística: http://www.acento.com.do/index. php/blog/1630/78/La-Cadena-Logistica.html

Calabuig, S. (2012, 01 18). El banano: la mejor forma de consumir potasio. Retrieved 10 04, 2013, from Vivir \& Salud : http://vivirsalud.imujer.com/3981/el-banano-la-mejor-forma-de-consumir-potasio

Comercio y Aduanas. (2012, 12 21). Comercio Exterior y Aduanas. Retrieved 11 15, 2013, from Comercio Exterior y Aduanas: http:/www.comercioyaduanas.com.mx/comercioexterior/comercioexterioryaduanas/116-que-es-comercio-exterior

El Comercio. (2014, 01 17). Política. Politica exterior de Ecuador priorizará relaciones con países de Asia, África y Latinoamérica, p. 1.

El Telégrafo. (2011, 07 11). Economía . Empresa china interesada en comprar banano ecuatoriano, pp. 1-2.

De Cordoba, J. (1995, Dec 06). Latin america's family empires --- Ecuador drama: Who'll run banana empire? --- Luis Noboa fought U.S. giants; now his heirs fight each other. Wall Street Journal. Retrieved from http://search.proquest.com/ docview $/ 398501219$ ?accountid $=50434$

Definición . (2010, 08 12). Definición de Exportacion. Retrieved 11 15, 2013, from Definición de Exportacion : http:// definicion.de/exportacion/

Diario HOY. (2008). Cinco Exportadoras Dominan el Negocio Bananero Local. HOY, 1-2.

Mecalux Esmena. (2012, 12 04). Integración tridimensional en la 'Supply Chain'. Retrieved 04 10, 2014, from Integración tridimensional en la 'Supply Chain': http://www.mecalux.es/articulos-de-logistica/integracion-tridimensional-en-la-supply-chain?idinterview $=13531262$ 
Ministerio de Comercio Exterior. (2012, 06 08). Ley de Comercio Exterior. Retrieved 11 28, 2013, from Ley de Comercio Exterior: http://comercioexterior.com.ec/qs/content/ley-de-comercio-exterior

Ministerio de Comercio Exterior. (2012, 06 08). Ministerio de Comercio Exterior. Retrieved 11 28, 2013, from Ley de Comercio Exterior: http://comercioexterior.com.ec/qs/content/ley-de-comercio-exterior

Osorio, L. L. (2012, 03 13). Solo C que nada C. Retrieved 10 04, 2013, from LA PRODUCCIÓN Y EXPORTACIÓN BANANERA DEL ECUADOR: http://solocquenadacbyllunao.blogspot.com/2012/03/la-produccion-y-exportacion-bananera. html

Padilla, L. (2013). Las exportaciones no petroleras en Ecuador crecieron en los primeros cuatro meses del 2013. Andes, 1-2.

Padilla, L. (2013, 05 21). Pequeños bananeros crean un consorcio de exportación certificada como 'Comercio Justo'. Andes, pp. 1-2.

Padilla, L. (2013). Pequeños bananeros crean un consorcio de exportación certificada como 'Comercio Justo'. Andes , 1-2. Portafolio. (2012). Aumentan exportaciones de banano hacia EE. UU. Portafolio Colombia, 1-2.

Portal Nautico. (2011, 03 15). Navieras . Retrieved 11 16, 2013, from Portal Nautico: http://www.portalnautico.net/navieras.htm

PRO MÉXICO . (2013, 06 22). PRO MÉXICO . Retrieved 04 06, 2014, from PRO MÉXICO INVERSION Y COMERCIO: http://www.promexico.gob.mx/es mx/comercio/Cadena de suministros y logistica de exportacion

PROECUADOR. (2013, 01 21). Características del Banano. Retrieved 10 04, 2013, from Sector Banano: http://www. proecuador.gob.ec/exportadores/sectores/banano/

Sanbrailo, J. (2012, 05 29). Latin Business Chronicle . Retrieved 04 10, 2014, from Ecuador: Never a Banana Republic : http://www.latinbusinesschronicle.com/app/article.aspx?id=5689

Silva, J. M. (2012, 08 01). La Casen y la visita de Milton Friedman. Retrieved 04 10, 2014, from DF.CL: http://m.df.cl/ la-casen-y-la-visita-de-milton-friedman/prontus_df/2012-07-31/194014.html

Valarezo, G. R., \& Torres Dávila, V. H. (2004). El Desarrollo Local en el Ecuador, Historia, Actores y Métodos. Quito: Ediciones Ayba Yala.

WorldFood Moscow. (2013, 09 15). 23rd International Food \& Drinks Exhibition. Retrieved 10 04, 2013, from WorldFood Moscow: http://www.world-food.ru/en-GB/ 
